\title{
Erratum to: Metabolic response to 36 hours of fasting in young men born small vs appropriate for gestational age
}

\author{
Sine W. Jørgensen - Charlotte Brøns • Les Bluck • Line Hjort • Kristine Færch • \\ Ajay Thankamony • Linn Gillberg • Martin Friedrichsen • David B. Dunger • \\ Allan A. Vaag
}

Published online: 13 November 2014

(C) Springer-Verlag Berlin Heidelberg 2014

\section{Diabetologia}

\section{DOI 10.1007/s00125-014-3406-6}

Unfortunately, an error was introduced into the Abstract. The complete Abstract is printed here, with the correction shown in red.

\begin{abstract}
Aims/hypothesis Being born small for gestational age (SGA) is associated with an increased risk of type 2 diabetes in an
\end{abstract}

The online version of the original article can be found under doi:10.1007/ s00125-014-3406-6.

S. W. Jørgensen $(\bowtie) \cdot$ C. Brøns $\cdot$ L. Hjort $\cdot$ L. Gillberg $•$ A. A. Vaag Department of Endocrinology (Diabetes and Metabolism), Rigshospitalet, Tagensvej 20, 2200 Copenhagen N, Denmark

e-mail: sinewanda@gmail.com

S. W. Jørgensen $\cdot$ K. Færch

Steno Diabetes Center, Gentofte, Denmark

L. Bluck

MRC Human Nutrition Research Unit, Cambridge, UK

\section{A. Thankamony \\ Department of Paediatrics, University of Cambridge, Cambridge, UK}

\section{Friedrichsen}

Department of Nutrition, Exercise and Sports, University of Copenhagen, Copenhagen, Denmark

\section{B. Dunger}

Institute of Metabolic Science, Department of Paediatrics, University of Cambridge, Cambridge, UK affluent society, but could confer an improved chance of survival during sparse living conditions. We studied whether insulin action and other metabolic responses to prolonged fasting differed between 21 young adults born SGA and 18 matched controls born appropriate for gestational age (AGA). Methods A frequently sampled IVGTT and indirect calorimetry measurements were performed after a $36 \mathrm{~h}$ fast. Endogenous glucose production, insulin sensitivity $\left(\mathrm{S}_{\mathrm{I}}\right)$, first-phase insulin secretion and glucose effectiveness were estimated by stable isotope tracer techniques and minimal modelling. Muscle and fat biopsies were obtained after $35 \mathrm{~h}$ of fasting. Results During fasting, SGA individuals experienced a more pronounced decrease in serum insulin and lower plasma triacylglycerol levels compared with AGA individuals. In addition, energy expenditure decreased in SGA but increased in AGA individuals. After fasting, SGA individuals displayed lower fat oxidation than AGA individuals. Glucose effectiveness $\left(\mathrm{S}_{\mathrm{G}}\right)$ was reduced in SGA compared with AGA individuals, whereas hepatic or whole body insulin action $\left(\mathrm{S}_{\mathrm{I}}\right)$ did not differ between groups. SGA individuals had increased muscle PPARGC1A DNA methylation. We found no differences in adipose tissue PPARGCIA DNA methylation, muscle and adipose tissue PPARGC1A mRNA expression, or muscle glycogen levels between the groups.

Conclusion Compared with AGA individuals, SGA individuals displayed a more energy-conserving and potentially beneficial cardiometabolic response to $36 \mathrm{~h}$ fasting. The role of increased muscle PPARGC1A DNA methylation in mediating this response requires further study. 